\title{
Supporting the measurement of the United Nations' sustainable development goal 11 through the use of national urban information systems and open geospatial technologies: a case study of south Korea
}

\author{
Junyoung Choi ${ }^{1}$, Myunghwa Hwang ${ }^{2}$, Gayeon $\mathrm{Kim}^{3}$, Janghwan Seong ${ }^{4}$ and Jaeseong $\mathrm{Ahn}^{5^{*}}$
}

\begin{abstract}
Background: Geospatial information has drawn substantial attention as a means for building a common measurement and monitoring framework that can be employed across different countries all over the world for the sustainable development goals (SDGs) of the United Nations (UN). Determining the appropriate spatial units for measurements is a critical issue, particularly for the goals associated with the safety, resilience, and sustainability of cities and human settlements. Open geospatial technologies are expected to help address this issue of spatial measurement since they comply with geospatial standards and can be easily adopted by both developed and developing countries.

Methods: This study evaluates the applicability of open geospatial technologies for the development of a common measurement framework for UN SDG 11. To this end, the study analyzes to what extent national urban information systems of Korea can support the measurement of the target goals and makes recommendations for how open geospatial data and technologies could fill the void that current systems cannot fill at present.
\end{abstract}

Results and discussion: The results of this study show that Korea's urban information systems have an architecture built upon a standard-based open platform and thus can be easily extended by other open geospatial technologies for new developments.

Conclusions: From the Korean case study findings, we concluded that open geospatial technologies could serve as an enabler for constructing a worldwide common framework for the measurement of sustainable development goals.

Keywords: UN, Sustainable development goals, Open geospatial technology, National spatial information systems, South Korea

\section{Background}

The sustainable development goals (SDGs) of the United Nations (UN) are a set of goals that will guide global development efforts in the years from 2016 to 2030. The 17 goals with 169 indicators include not only existing millennium development goals (MDGs) such as no poverty, zero hunger, good health, but also broader goals pertaining to water, the environment, industrialization, urbanization,

\footnotetext{
* Correspondence: jsahn@kiu.ac.kr

${ }^{5}$ Department of Geoinformatics Engineering, Kyungil University, Gyeongsan-si, South Korea

Full list of author information is available at the end of the article
}

etc. These goals cover a broad range of sustainable development issues, and it is hoped that governments will use these goals to fight against extreme poverty and address the challenges of ensuring environmentally, socially, and economically sustainable development in their respective communities. Crucial to the success of the SDGs will be strong government systems and, in particular, strong statistical systems that can measure and incentivize progress across the goals [1]. The production and use of quality data is therefore becoming increasingly recognized as being a fundamentally important task for the measurement, monitoring, and tracking of the SDGs. 
The need for geospatial information in sustainable development processes has been evident in recent years (e.g., [2]). This information can describe where people are and their spatial relationship to each other, and this can in turn help governments to develop goal achievement plans and measure and monitor outcomes. Comprehensive geospatial information is especially important for supporting the measurement, monitoring, and tracking processes for the SGDs. The purpose of geospatial information in these processes is two-fold. First, geospatial information is used to monitor the proposed indicators of the SDGs at various spatial scales including the global-, national-, and subnational-levels (e.g., for cities and states/provinces). Second, many of the SDG indicators have geospatial characteristics, so geospatial data and technologies are needed to measure them adequately. Despite the recognized need for geospatial information in monitoring of the SDGs, the integration and implementation of geospatial information remains a challenge.

Open geospatial data and technologies are expected to be useful for implementing a geospatial information-based monitoring framework for the SDGs. Both developed and developing nations will be asked to monitor the implementation of the SDGs based on their national spatial data infrastructure (NSDI), but many developing nations will likely find this task difficult because of financial and technical problems. Thus, open geospatial technologies could help to alleviate this burden for developing countries because the access costs for data and software used to implement the NSDI are typically much lower when such technologies are employed. The use of open geospatial technologies could also help to make the methods and results for SDG measurements globally interoperable since they comply with open geospatial standards.

Despite the need for geospatial information and open geospatial technologies in the measurement and monitoring of the SDGs, there are few studies that specify what types of geospatial information and technologies are needed and how such information and technologies should be provided. This paper examines the possibility of utilizing open geospatial technologies in the field of urban planning and management for the measurement and monitoring of the SDGs. In particular, this paper focuses on SDG 11, which aims to "Make cities inclusive, safe, resilient and sustainable." This focus was selected for two key reasons. First, urbanization is now global in scale and urban SDGs such as SDG 11 would strengthen other SDGs as well [3]. Second, the measurement and monitoring of SDG 11 would involve geospatial information, since it requires location-specific decision making support tools related to territorial planning and management.

In this paper, we first review the literature that documents the need for geospatial information in the measurement and monitoring of the SDGs. Second, we examine the national urban information systems of Korea. Lastly, we evaluate how Korean urban information systems can be used for the measurement of SDG 11. Specifically, the evaluation focuses on the availability of open data and analysis functions that are applicable to the derivation of SDG 11 indicators, as well as the compliance of those data and functions with open standards. For feasibility, our evaluation only focuses on South Korea. The case of South Korea is of special interest to us since some local Korean governments have developed their own urban information systems by implementing standard system models defined by the Korean central government. Overall, we think this process of sharing standard system models in Korea will have meaningful implications with regard to the establishment of a global common framework necessary to support the measurement and monitoring of the SDGs.

\section{Literature review}

This section explores the literature involving SDG measurements and discusses how geospatial information could contribute to resolving the data challenge associated with SDG measurements. Then, the literature on urban information systems (UIS) is examined in relation to SDG measurements and open geospatial technologies.

\section{Needs for geospatial information in measuring SDGs}

Measuring SDGs is an essential task for the UN and its member countries. In particular, the ability of measuring SDGs in cities has become critically important these days. According to Aromar Revi [3], in expert meeting on Regional Preparations for Habitat III there are at least five reasons why SDGs need to be measured in cities. First, urbanization is now a global-scale process that affects the sustainability of our planet. Second, the engagement of urban residents are necessary for the successful practice of policy or civil actions to strengthen the sustainability of our society. Third, an urban SDG would be useful for motivating public-private partnerships (PPP) to participate in the achievement of the SDGs. Fourth, if urban issues are addressed separately instead of collectively with broad SDGs, the role and impact of cities may become diluted in the overall process. Lastly, an urban SDG could help to strengthen other SDGs and promote linkages among them especially in areas where the goals are linked or are interdependent on each other.

One big challenge for the measurement of the SDGs concerns the lack of suitable data for various dimensions of development. This challenge was particularly acute during the early attempts at MDG measurements. Scott and Rajabifard [2] discussed how MDGs often failed to recognize the need for data and geographic information, and they found that it was difficult for countries to track and monitor the changes in the MDGs consistently. The 
United Nations (UN) Committee of Experts on Global Geospatial Information Management (UNGGIM) also remarked that poor data quality, lack of timely data, and the unavailability of disaggregated data on important dimensions were among the major challenges for measuring sustainable development [4].

The literature review findings suggest that geospatial information could play an important role in overcoming the aforementioned data challenges and in strengthening the capabilities of governments and agencies that are tasked with analyzing and reporting on the SDGs. In fact, the final 2015 MDG Report raises the need for geospatial information and notes that geospatial data can support monitoring in many aspects of development [5]. In the Future We Want report, the UN emphasized the importance of the use of geospatial technologies for driving sustainable development and supporting datadriven evidence-based policy making [6]. Recent studies have indicated that geospatial big data from various social network services such as Twitter, Facebook, etc. could enhance our understanding of sustainable development progress in cities by enabling real-time analysis and monitoring of urban activities and changes [7-9].

In the literature, several studies have highlighted the necessity of policy and institutional frameworks in enabling the provision and utilization of geospatial information for SDG measurements. For example, the UNGGIM suggested that the production and use of geospatial information within national, regional, and global policy frameworks should be mainstreamed in order to enhance the capabilities of institutions to analyze, model, monitor, and report on sustainable development progress, disasters, climate change impacts and adaptation measures, and other global concerns [10]. The UN also recommended that participating countries should consider the ways to build and provide disaggregated, high quality, reliable data [11]. Scott and Rajabifard [2] remarked that the global geospatial information communities, especially through national geospatial information agencies, have their own opportunity to integrate geospatial information into the UN global development agenda in a more holistic and sustainable manner.

\section{Urban information systems and open geospatial technologies}

Urban information systems collect, analyze, produce, and manage various information products pertaining to social, economic, and environmental phenomena in urban areas. Potentially, UIS can serve as data providers, analytic engines, and information-sharing platforms for the measurement and monitoring of the SDGs.

In general, UIS, especially the ones reviewed in this study, can be classified into the following three groups: systems related to (i) the management of urban infrastructure, (ii) environmental analysis, and (iii) urban analysis. The first group corresponds to information systems that local governments often develop for the efficient management of urban infrastructure such as waterworks, sync halls, and dangerous districts. The second group can be exemplified by the Geo Bolivia project, which is an effort to build online portals of environmental resources for developing countries as a way of providing assistance for their capacity building efforts. The last group concerns urban analysis, and related examples include the Online What if Planning Support System, ${ }^{1}$ the National Aeronautics and Space Administration's (NASA's) World Wind 3D Platform, ${ }^{2}$ and the World Bank's Platform for Urban Management and Analysis (PUMA) ${ }^{3}$ [12].

Recently, open geospatial technologies have made substantial contributions to all types of UIS (Fig. 1). In particular, they have proven to be useful for the development of information systems in that such technologies have provided the software tools, libraries, and frameworks needed for implementing client and server applications. The common nature of these technologies lies at compliance with open geospatial standards, which improves the interoperability of geospatial data and functions among UIS.

\section{National urban information systems of Korea}

This section provides background information on national UIS with data and analytical capabilities that can be potentially used in the measurement of SDG 11 . Specifically, we examine four systems including the KOrea Planning Support System (KOPSS), Urban Planning Information System (UPIS), U-City project, and Spatial Big Data System (SBDS), as they are closely related to collecting information of regional planning, urban policies, and big data activities. The focus of our examination is on the characteristics of the geographic data, spatial analysis functions, open access to data and functions, and compliance to standards in each system.

\section{Korea planning support system (KOPSS)}

The KOPSS is a decision-support system that can provide analytical solutions for spatial problems involved in local policy making [13]. In particular, it has spatial analytical capabilities that are necessary to address policy problems related to facility allocation, land use planning, urban revitalization, urban landscape management, etc. The Ministry of Land, Infrastructure, and Transport (MOLIT) of Korea started the KOPSS project in 2006 to enhance the practice of urban and regional planning with evidencebased scientific decision-making in local governments [14].

One notable feature of KOPSS is its data mart. A KOPSS data mart contains detailed, linked spatial data for a target region. In particular, these data include 


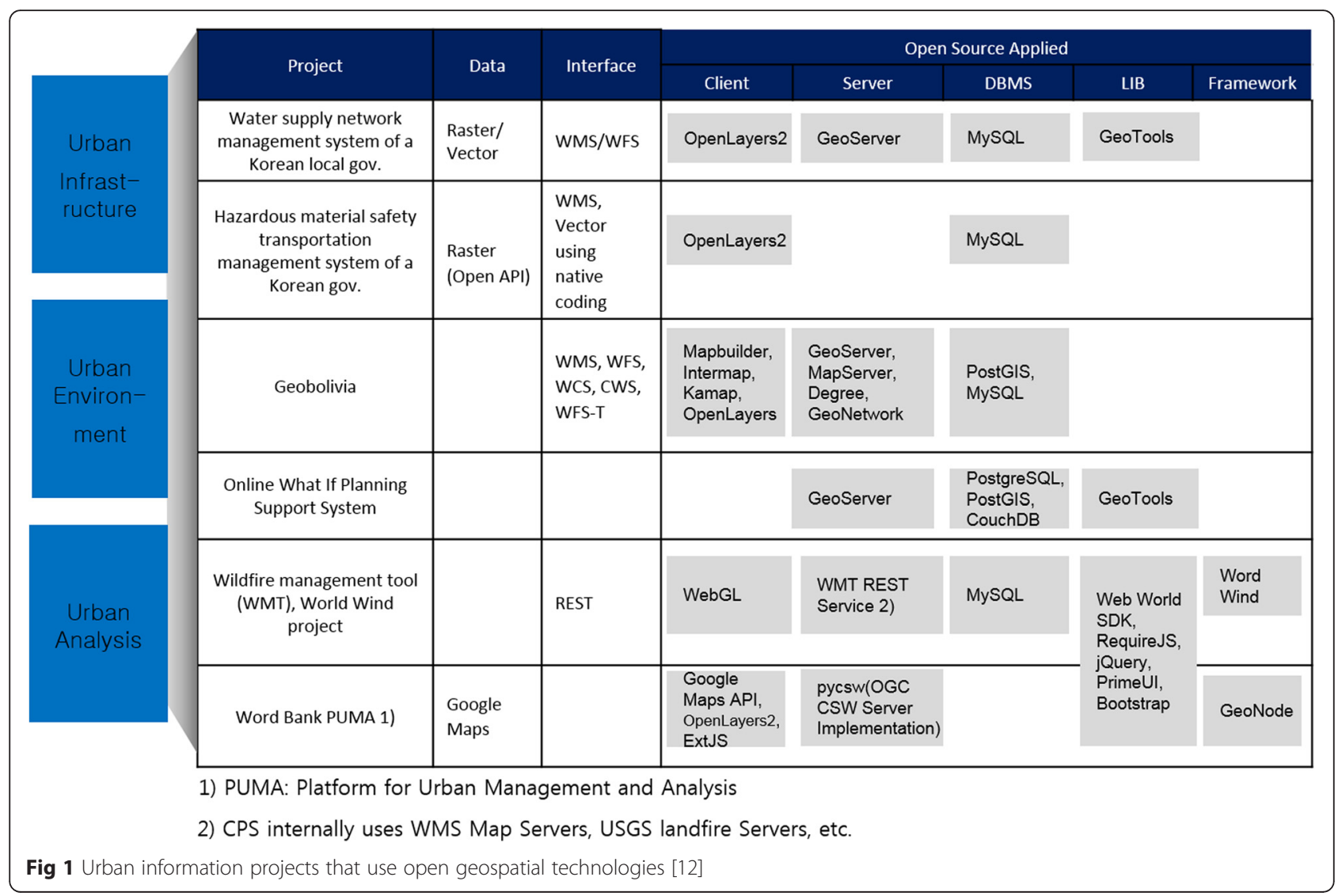

cadastral maps, building boundaries and registers, population registries, roads, facilities, and regional indicators [15]. Attributes and statistics of real world objects in the data mart are aggregated in the form of administrative or statistical boundaries. Transportation networks are mostly in the structure of node-links for efficient calibration of accessibility indicators. From an analysis viewpoint, the KOPSS data mart is beneficial since land parcels, buildings, populations, and related register documents are spatially linked with parcels as unit locational references.

In terms of spatial analysis functions, KOPSS has 147 unit functions for geometry processing, vector data analysis, raster analysis, spatial statistics, population growth modeling, Huff modeling, etc. [16]. Each unit function is in the form of a Web Processing Service (WPS) Application Programming Interface (API), which is an Open Geospatial Consortium (OGC) web service standard. To provide a user interface to the 147 WPS APIs, KOPSS runs a web application that serves as a wizard for guiding analysis steps.

The ownership of KOPSS mostly belongs to a local government that operates the system. This is particularly true of a data mart since it needs to be constructed for individual regions. Data accessibility is rather limited in KOPSS because local governments need to take actions to supply detailed data while protecting against invasions of privacy. Unlike a data mart, the analysis APIs of KOPSS are open to the public and are the same across regions.

\section{Urban planning information system (UPIS)}

For sustainable and sound urban development, there needs to be systems in place to prevent the inappropriate development of national lands, provide tools for national land use regulation, and monitor the development activities of local governments. The UPIS manages information for urban planning by Korean governments [17]. This system was fully implemented after several pilot and research projects. Korea's central government has been developing a standardized form of UPIS since 2008 and is distributing it to local governments. The system uses data from urban plans and collections of geographic data from parcel-based land use zoning programs. To support the business of urban land use regulation, UPIS enables spatial operations such as queries and overlays to be performed with urban planning data. Nowadays, local governments apply the open data policy to UPIS data and provide its data to the public through internet portals. Through such data sharing, governments expect that civic organizations will check urban planning policies out and monitor the related changes in urban 
space. The client application of UPIS provides open APIs for simple spatial analysis, which conform to the WPS standard of the OGC. Users of the APIs can retrieve data and statistics on buildings and land uses. They can also import and export maps and apply arithmetic operations to the counts and areas of buildings and land use zones [18].

\section{The U-city project}

U-City is a new type of urban development that overcomes the fundamental limitations of conventional cities by implementing converging cutting-edge information and construction technologies into urban spaces. The project aims to create sustainable and human-oriented cities, which have compact, healthy, secure, green, and networked features [19]. In Korea, U-Cities are being implemented mainly in new towns because of the prohibitive financial costs and development conditions in established city areas [20]. The ultimate vision Korea's U-City project is to improve the quality of life and competitiveness of cities through the construction of cutting-edge information centers. Citizens in U-Cities are expected to experience ubiquitous services anywhere and anytime by the help of intelligent city infrastructure that can collect and process various information about the environments and activities within the city. The city services are implemented by converging construction and information technologies into the building process of roads, traffic, schools, hospitals, and urban facilities. To enable U-City services, urban integrated operation centers (UIOCs) collect, process, and monitor information on the various dimensions of the city environments. U-Cities collect environmental and traffic data in near real time from environmental sensors and traffic detectors and merge the resulting observational data with UIS data. While U-Cities operate in a data-intensive manner, they often prohibit the sharing of some of the data for the protection of personal information. Information systems used for U-City operation make use of basic geographic information system (GIS) operations, but not a full spectrum of spatial analytical functions. Recently, new efforts are being put forth to integrate the data and analytical functions among U-City systems and legacy UIS.

\section{Spatial Big data system (SBDS)}

The SBDS is another MOLIT-led project that aims to provide a platform infrastructure where various data from public and private sources are transformed into big spatial datasets that can be employed for spatiotemporal analyses [21]. Through work on the SBDS since 2014, MOLIT is attempting to address the increasing demands from diverse policy domains for big spatial data and analyses, such as in the optimization of public transportation systems for improved commuting, timely supply of affordable housing data customized to different needs of local citizens, etc.

As common infrastructure for government users, the SBDS focuses on constructing and providing new types of big spatial data through location-based integration of business data (e.g., real estate transaction registers) and spatial data (e.g., land parcels) from national information systems, as well as through mashups of big data in the public and private domains (e.g., time series data of the geographic distributions of cell phone users). At present, the SBDS makes online or offline connections to other national information systems for regular collections and updates of raw data. It then applies various geocoding mechanisms to the collected data so as to enable ondemand, location-based mashups of different raw datasets. As of December 27, 2015, the SBDS provides 15 types of new pre-built databases in support of policy analyses in the public domains of real estate, transportation, and regional development [21]. These pre-built databases include statistics for administrative or statistical units, road networks in a node-link structure, and original attributes of point-referenced parcels and buildings.

The SBDS also seeks to serve as an analytical platform where government users can distribute massive spatial datasets across multiple computer machines and carry out spatial analyses against those distributed datasets in a concurrent manner. To provide a high-performance computing environment, the SBDS encompasses a Hadoop system for distributed spatial data processing, which is an extension of the spatial Hadoop open source platform [21]. This Hadoop system currently has eight basic spatial operations (e.g., distance, convex hull, clip, spatial join) and six advanced ones (e.g., point density, location-allocation, hotspot detection) for distributed spatial data processing. The SBDS complies with the conditions of an open source platform, but the lack of open standards for big spatial data systems limits its openness in terms of standards.

The SBDS is at an early stage of development with regard to its functions, operations, and legal foundations. Thus, the accessibility of its data and spatial analysis functions is currently limited to government users. Nonetheless, it is expected that the SBDS, once established, will strengthen the capabilities of policy makers and practitioners to design, fulfill, monitor, and evaluate novel policies from data-driven evidence (e.g., derivation of optimal routes for overnight city buses based on mobile phone user data, networking of industry clusters across regions from firm-based transaction data).

\section{Methods}

This section explains the methods used for evaluating national UIS and presents the evaluation results. Then, 
the role of open geospatial technologies in measuring and monitoring SDG 11 indicators with Korean UIS is discussed.

\section{Evaluation method}

The evaluation of national UIS focused on four aspects, namely, the characteristics of geospatial data, openness, analysis functions for the measurement of the SDG indicators, and applied geospatial standards (Table 1). The national UIS use various geographic units for data collection and analysis. In comparison, the SDG indicators are measured by using geospatial data collected mostly on administrative or statistical units. Thus, an evaluation is needed to determine whether a national UIS is able to provide data at the geographical units necessary to measure the SDG indicators.

The openness of geospatial data is another crucial characteristic of UIS data for our evaluation since openness can encourage SDG measurement across public and private sectors. The more open the geospatial data is, the more contributions the data would likely make when measuring SDG indicators.

The third aspect of our evaluation concerns spatial analysis functions of national UIS. This is because some SDG indicators can be produced only after intensive spatial analyses. Spatial analysis functions of national UIS under our evaluation include summary and descriptive statistics, simple overlay functions, and complex spatial data analysis methods. The more spatial analysis functions a national UIS support system has, the more SDG indicators we can measure with it.

The final criterion of our evaluation deals with the issue of standards. National UIS utilize multiple geospatial data sources such as digital maps, official statistics, and data from private sectors. To allow users to make full use of these geospatial data sources, the data from these sources need to be provided in an easily accessible, interoperable, and combinable manner. Standards for geospatial data and technologies help users integrate different types of geospatial information, in addition to facilitating consistent data access. National UIS, if they are built upon geospatial standards, would be interoperable with each other, thus being capable of communicating and exchanging geospatial data from one system to another. The more that a UIS conforms with geospatial standards, the less it would cost to obtain data and undertake spatiotemporal analyses with such data for SDG measurements.

\section{Results and discussion}

\section{Spatial units, spatial measurements, and objects of measurements}

According to our evaluation, SDG 11 indicators need to be measured in the geographical units of nodes/links, administrative or statistical boundaries, user-defined aggregation units, points, radii, and parcels (Table 2). Except for nodes/links and points, other units could be considered as a form of spatial boundary. If there were no spatial data available, then we could measure SDG 11 indicators by using Earth observation data. Additionally, individual records (e.g., building registries) could be aggregated by some sort of areal unit. In contrast, aggregated data could be used as individual data. In that case, this may lead to ecological fallacies in social science terms or modifiable areal unit problems (MAUP) in geospatial science. Therefore, it is necessary to set a measurable geographic unit, which can avoid such problems.

For geographic measurements, the indicators 11.1, $11.5,6,67,68$, and 69 can be measured through spatial analyses, whereas the indicators $11.2,11.3,11.6,6,70$, and 71 are statistically measurable. This means, for example, if we try to measure indicator 11.1 and 11.5, we need to carry out data gathering, data cleansing, and spatial analysis with a UIS. Statistically measurable indicators can be obtained from statistical data of a UIS, and we can visualize them on thematic maps with administrative or other boundaries.

\section{Data openness}

We categorized data openness into the following four levels: open data, limited open data, permitted open data, and not available (Table 3). The level of "open data" means that data and indicators are open to the public, and the indicators $11.4,67,69$, and 70 belong to this category. The level of "limited open data" means that the entire dataset is not open to the public, but related data are open in an aggregated fashion. The indicators $11.1,11.5,6$, and 71 belong to this category. The level of "permitted open data" means that data and indicators are available but are subject to the issues of private information and permissions. In South Korea, the locations of low-income households are provided by permission, for example, so we categorized indicator 66 as permitted open data. The level of "not available" means that the indicators cannot be measured since they are qualitative or data is unavailable. The indicators 11.2, 11.3 , and 11.6 belong to this last category.

Table 1 Evaluation criteria for urban information systems (UIS)

\begin{tabular}{|c|c|c|c|}
\hline Geospatial data & Openness & Spatial analysis functions & Standard \\
\hline $\begin{array}{l}\text { Whether the geographical unit of geospatial } \\
\text { data at UIS are suitable for SDG measurement }\end{array}$ & $\begin{array}{l}\text { The openness } \\
\text { of UIS data }\end{array}$ & $\begin{array}{l}\text { Whether UIS have the spatial analysis } \\
\text { functions needed for SDG measurement }\end{array}$ & $\begin{array}{l}\text { Whether UIS adopted } \\
\text { geospatial standards }\end{array}$ \\
\hline
\end{tabular}


Table 2 The objects of measurement and geographic units for Sustainable Development Goal 11 (SDG 11) indicators

\begin{tabular}{|c|c|c|c|}
\hline SDG 11 indicators & Objects of measurement & $\begin{array}{l}\text { Geographic } \\
\text { unit }^{\mathrm{a}}\end{array}$ & Measurement $^{\mathrm{b}}$ \\
\hline 11.1. Number of street intersections per square kilometer. & $\begin{array}{l}\text { Street density, street safety, and public space in } \\
\text { cities. }\end{array}$ & Node/Link & SA \\
\hline $\begin{array}{l}\text { 11.2. Existence and implementation of a national urban } \\
\text { and human settlement policy framework. }\end{array}$ & $\begin{array}{l}\text { Government's commitment to sustainable urban } \\
\text { development and safe and sustainable human } \\
\text { development. }\end{array}$ & A & Sta \\
\hline $\begin{array}{l}\text { 11.3. Percentage of cities with more than } 100,000 \\
\text { inhabitants that are implementing risk reduction } \\
\text { and resilience strategies informed by accepted } \\
\text { international frameworks. }\end{array}$ & $\begin{array}{l}\text { Disaster and climate preparedness of the city, to } \\
\text { be updated in accordance with the new Hyogo } \\
\text { framework. }\end{array}$ & A & Sta \\
\hline $\begin{array}{l}\text { 11.4. Presence of urban building codes stipulating either } \\
\text { the use of local materials and/or new energy efficient } \\
\text { technologies or with incentives for the same. }\end{array}$ & $\begin{array}{l}\text { Sustainable local production and consumption } \\
\text { of raw materials and low-carbon development. }\end{array}$ & A & Sta \\
\hline $\begin{array}{l}\text { 11.5. City biodiversity index (Singapore index): Green space } \\
\text { and biodiversity are crucial for a healthy urban } \\
\text { environment. }\end{array}$ & $\begin{array}{l}\text { Protection of endemic species as well as the } \\
\text { environmental health of the city. }\end{array}$ & $\mathrm{D}$ & SA \\
\hline $\begin{array}{l}\text { 11.6. Percentage of consumption of food and raw materials } \\
\text { within urban areas that are produced and delivered } \\
\text { in/from rural areas within the country. }\end{array}$ & $\begin{array}{l}\text { Linkages between rural and urban areas, and the } \\
\text { health of their codependence vis-a-vis the national } \\
\text { economy. }\end{array}$ & $\mathrm{D}$ & Sta \\
\hline \multicolumn{2}{|c|}{$\begin{array}{l}\text { Indicator } 6 \text { cross-reference: Losses from natural disasters caused by climate and non-climate related events } \\
\text { (in US\$ and in lives lost) }\end{array}$} & Point & Sta/SA \\
\hline \multicolumn{2}{|c|}{ Indicator 66: Percentage of the urban population living in slums or informal settlements } & A & SA \\
\hline \multicolumn{2}{|c|}{ Indicator 67: Percentage of people within 0.5 km of public transit running at least every 20 min. } & Radius & SA \\
\hline \multicolumn{2}{|c|}{ Indicator 68: Ratio of the land consumption rate to population growth rate at comparable scales. } & A & SA \\
\hline \multicolumn{2}{|c|}{ Indicator 69: Mean urban air pollution level for particulate matter (PM10 and PM2.5). } & A/Point & SA \\
\hline \multicolumn{2}{|c|}{ Indicator 70: Area of public and green space as a proportion of total city space. } & $\begin{array}{l}\text { Parcel, statistical } \\
\text { boundary }\end{array}$ & Sta \\
\hline \multicolumn{2}{|c|}{ Indicator 71: Percentage of urban solid waste regularly collected and well managed. } & $\mathrm{D}$ & Sta \\
\hline
\end{tabular}

${ }^{a}$ A: Administrative boundary, D: Defined aggregation unit

${ }^{\mathrm{b}}$ Sta: Statistically measurable, SA: Spatial analysis

Table 3 Data openness and the availability of spatial analysis functions for SDG 11 indicators

\begin{tabular}{|c|c|c|c|c|c|}
\hline \multirow{2}{*}{$\begin{array}{l}\text { SDG } 11 \\
\text { indicators }\end{array}$} & \multirow[t]{2}{*}{ Data openness } & \multicolumn{4}{|c|}{ Availability of spatial analysis functions $^{a}$} \\
\hline & & KOPSS & UPIS & U-City & SBDS \\
\hline 11.1 & Limited open data & $\mathrm{O}$ & $x$ & $\mathrm{O}$ & $x$ \\
\hline 11.2 & Not available & $\mathrm{O}$ & $x$ & $x$ & $\mathrm{O}$ \\
\hline 11.3 & Not available & O & $\mathrm{O}$ & $x$ & $x$ \\
\hline 11.4 & Open data & $x$ & $x$ & $x$ & $x$ \\
\hline 11.5 & Limited open data & O & 0 & $x$ & $\mathrm{O}$ \\
\hline 11.6 & Not available & $x$ & $x$ & $x$ & $x$ \\
\hline 6 & Limited open data & $x$ & $x$ & $x$ & $\mathrm{O}$ \\
\hline 66 & Permitted open data & $\mathrm{O}$ & $\mathrm{O}$ & $x$ & $x$ \\
\hline 67 & Open data & O & $\mathrm{O}$ & - & $\mathrm{O}$ \\
\hline 68 & Available data & $\mathrm{O}$ & $\mathrm{O}$ & $\mathrm{O}$ & $\mathrm{O}$ \\
\hline 69 & Open data & $x$ & $x$ & $\mathrm{O}$ & $x$ \\
\hline 70 & Open data & $\mathrm{O}$ & $\mathrm{O}$ & $\mathrm{O}$ & $x$ \\
\hline 71 & Limited open data & $x$ & $x$ & $\mathrm{O}$ & $x$ \\
\hline
\end{tabular}




\section{Geospatial standards}

In South Korea, there are about 123 geospatial standards, and these include both domestic and international ones. They address the subjects of geospatial data construction, geospatial service implementation, and data quality management. Most of the domestic standards are based on international references defined by the International Organization for Standardization (ISO) or the OGC.

The information systems to monitor, measure, and track the SDG indicators need to adopt a wide range of geospatial standards. Two essential types of standards are those related to geospatial data construction and geospatial services, which would have impacts respectively on database development and the data distribution of the SDG indicators.

Table 4 shows the geospatial standards applied to Korean UIS under our evaluation. The findings reveal that the standards adopted by the evaluated UIS are mostly concerned with geospatial services. In comparison, the standards related to geospatial data construction are few. Two reasons underlie this result. First, the evaluated systems seek to provide geospatial services needed to support policy making and administrative activities in the areas of urban planning, utility management, land management, and civil services. The main functions of the systems focus on the methods for geospatial data management and analysis/visualization services. Second, among Korean geospatial standards, the portion of standards pertaining to geospatial data contents is relatively small. Additionally, Korean standards of geospatial data construction and quality management remain abstractlevel standards and have limits when applied to the development of geospatial information systems. Nevertheless, we examined the kinds of geospatial standards adopted by KOPSS, UPIS, U-City, and SBDS to evaluate the multi-source geospatial data accessibility, interoperability, and integration capacity of these systems.

\section{Spatial analysis functions}

In terms of spatial analysis functions, we assessed whether a UIS provides the functions necessary for measuring SDG 11 indicators or if the UIS analysis functions are extensible to support the measurement.

Table 4 Adoption of geospatial standards by Korean urban information systems (UIS)

\begin{tabular}{ll}
\hline UIS & Geospatial standards \\
\hline KOPSS & GML, WMS, WFS, WCS, SLD, Symbology \\
& Encoding, Filter Encoding \\
UPIS & GML, SLD, WFS, WMS \\
U-City & GML, SLD, WFS, WMS \\
SBDS & GML, SLD, WFS, WMS \\
\hline
\end{tabular}

According to the assessment results shown in Table 3, KOPSS and UPIS can be used to measure similar types of indicators. However, KOPSS seems to be slightly superior since it contains more analysis functions than UPIS and its functions can be combined flexibly for complex analyses. U-City has advantages in terms of measuring environment-related indicators but disadvantages in terms of statistical measurements. The SBDS is rather weak for statistical and environment-related measurements.

\section{Conclusions}

Our evaluation shows that Korean UIS are applicable to measuring and monitoring SDG 11 indicators to some extent. Geospatial data of the evaluated systems support various geographic units of data collection and analysis, which is a key requirement for SDG measurements. Some of the systems are also equipped with functions capable of analyzing SDG 11 indicators, and they provide open geospatial data and comply with standards for geospatial services.

The results of our study indicate that a UIS based on standardized open geospatial technologies could provide useful tools for SDG measurements. Often, statistical indicators are considered the only information resource needed for SDG measurement and monitoring. However, in developing countries statistical institutions tend to have difficulties producing new statistics and lack capacities to build institutional and practical foundations needed for SDG measurement. In addition, statistical data tend to be conditionally open, and this often prohibits citizens and civic organizations from accessing the raw data and cross-checking them with geospatial data. Since collaborations between public and private sectors seem essential to measure SDGs, the limited accessibility of statistical data may serve as an obstacle. In this context, the combined use of national UIS based on open geospatial technologies would present a supplemental solution for the development of information infrastructure for SDG measurement and monitoring.

Despite their potential, our study also indicates that UIS still have many limitations in terms of enabling the complete implementation of SDG measurements at least in Korea. We think open geospatial technologies could help to overcome such limitations. For example, it is likely inevitable that Korean UIS will undergo a substantial amount of modification work in order to fully support SDG measurements. Since free and open source GIS software provides a variety of geospatial functionality, such as for data construction, management, sharing, and utilization, it would be cost-effective to utilize free and open source GIS software in supplementing Korean UIS. 
Open geospatial technologies would also be beneficial for strengthening the capabilities of Korean UIS in terms of geospatial data openness and geospatial standardization. Some free and open source GIS software programs feature compliance with ISO/OGC standards related to the distribution and sharing of geospatial data. In particular, the ISO 191xx series of geographic information standards and OGC standards such as data delivery standards, data format standards, and data search standards are implemented in desktop GIS, web mapping toolkits, web map servers, and spatial database management systems, some of which are free and open source GIS software. If these standard-based open geospatial software programs are integrated with Korean UIS of a standardized architecture to develop a common platform for SDG 11 measurement, the resulting platform would feature data and technological openness in its nature and it could be diffused more easily across regions. This Korean model would also be readily adaptable to developing countries, thus helping to bridge the geospatial technological gaps between developing and developed countries. In the near future, we think that new efforts are needed to develop an open platform for measuring quality of life indicators, including SDGs, similar to the activities for establishing the OGC Smart City platform.

\section{Endnotes}

${ }^{1}$ http://aurin.org.au/projects/portal-and-infrastructure/ what-if/ (accessed on March 20, 2016)

${ }^{2}$ http://goworldwind.org/ (accessed on March 20, 2016)

${ }^{3}$ https://puma.worldbank.org/ (accessed on March 20, 2016)

\section{Competing interests}

The authors declare that they have no competing interests.

\section{Authors' contributions}

JA designed the evaluation of urban information systems in South Korea. JC carried out the evaluation, and participated in the literature review. $\mathrm{MH}$ and GK fulfilled the survey of national urban information systems for evaluation, and participated in the literature review. JS articulated the motivations of the study and carried out result interpretation.

\section{Acknowledgement}

This work was supported by the National Research Foundation of Korea Grant funded by the Korean Government (NRF-2014S1A5B6037980).

\footnotetext{
Author details

${ }^{1}$ Spatial Information Office, Korea Land and Housing Corporation, Jinju-si; Spatial Big Data Center, Ministry of Land, Infrastructure and Transportation, Sejong-si, South Korea. ${ }^{2}$ Korea Research Institute for Human Settlements, Anyang-si, South Korea. ${ }^{3}$ Transportation and Logistics Research, Incheon Development Institute, Incheon-si, South Korea. ${ }^{4}$ National Territorial and Regional Planning Research, Land and Housing Research Institute, Daejon-si, South Korea. ${ }^{5}$ Department of Geoinformatics Engineering, Kyungil University, Gyeongsan-si, South Korea.
}

Received: 12 February 2016 Accepted: 27 April 2016

Published online: 06 May 2016

\section{References}

1. Sustainable Development Solutions Network (SDSN). Data for development: A needs assessment for SDG monitoring and statistical capacity development. New York: SDSN; 2015.

2. Scott G, Rajabifard A. Integrating geospatial information into the 2030 agenda for sustainable development. Jeju: Twentieth United Nations Regional Cartographic Conference for Asia and the Pacific; 2015. 6-9 October 2015.

3. Revi A. The post-2015 development agenda and the importance of the urban SDG: expert meeting on regional preparations for Habitat III. Jakarta: UNGGIM; 25 November 2014. (https://www.youtube.com/watch?v= XQQIhJegA4U). Accessed 20 Mar 2016.

4. UN Committee of Experts on Global Geospatial Information Management (UNGGIM). Monitoring sustainable development: Contribution of geospatial information to the Rio+20 processes. UNGGIM. 2012. (http://ggim.un.org/ 2nd\%20Session/GGIM\%20paper\%20for\%20Rio_Background\%20paper_ 18May\%202012.pdf). Accessed 20 Mar 2016.

5. United Nations (UN). The millennium development goals report 2015. UN. (2015a). (http://www.un.org/millenniumgoals/). Accessed 20 Mar 2016.

6. United Nations (UN). The future we want. UN. 2012. (http://www.uncsd2012. org/content/documents/727The\%20Future\%20We\%20Want\%2019\% 20June\%201230pm.pdf). Accessed 20 Mar 2016.

7. Hwang M. Spatiotemporal analysis of unstructured big data for public opinion monitoring. Korea: Korea Research Institute for Human Settlement; 2014.

8. World Bank, World Bank Group, Second Muse. Big data in action for development. Washington: World Bank; 2015.

9. Hollander JB, Renski H. Measuring urban attitudes using Twitter: An exploratory study. Cambridge: Lincoln Institute of Land Policy; 2015.

10. UN Committee of Experts on Global Geospatial Information Management (UNGGIM). Activities related to sustainable development and the post-2015 development agenda. UNGGIM. 2014. (http://ggim.un.org/docs/meetings/ GGIM4/13_SD\%20Agenda\%20ltem\%20Brief.pdf). Accessed 20 Mar 2016.

11. United Nations (UN). Transforming our world: The 2030 agenda for sustainable development. New York: UN; 2015b.

12. Choi J, Kim H, Ahn J, Kim J. FOSS4G for rapidly urbanizing cities and UN sustainable development goals (SDGs); SDG 11 cities and human settlement. Seoul, Korea: LH-OSGeo Joint Seminar: Open Source GIS for UN and Developing Countries; 2015.

13. Korea Research Institute for Human Settlements (KRIHS). The 2014 report on constructing the Korea planning support system. Korea: Ministry of Land, Infrastructure, and Transport (MOLIT); 2014.

14. Korea Research Institute for Human Settlements (KRIHS). The 2006 report on constructing the Korea planning support system - an executive summary. Korea: MOLIT; 2006.

15. Korea Research Institute for Human Settlements (KRIHS). The 2009 report on constructing the Korea planning support system. Korea: Ministry of Land, Infrastructure, and Transport (MOLIT): 2009.

16. Korea Research Institute for Human Settlements (KRIHS). The KOPSS open API - version 3.0. Korea: KRIHS; 2014.

17. Ministry of Land, Transportation, and Marine Affairs (MLTM). Urban planning information system. Korea: MLTM; 2008.

18. Ministry of Land, Transportation, and Marine Affairs (MLTM). Standard open API of the urban planning information system. Korea: MLTM; 2008.

19. Kim H. Future of converged spatial information in ubiquitous city. (LH), Korea: Korea Land and Housing Corp; 2012.

20. Choi J. Urban big data for smart city management. Daegu-si, South Korea: Winter conference of the Korean Association for Public Administration (KAPA); 2014.

21. Ministry of Land, Infrastructure, and Transport (MOLIT). The 2014 report on constructing the spatial big data system. Korea: MOLIT; 2015. 